Original Article

\title{
ANTIBACTERIAL ACTIVITY OF THE METABOLITES OF ASPERGILLUS CHEVALIERI AND TRICHODERMA HARZIANUM
}

\author{
EMELIA OPPONG BEKOE1* ${ }^{*}$, MICHAEL WIAFE-KWAGYAN², JOYCELYN GAYSI1
}

1Department of Pharmacognosy and Herbal Medicine, School of Pharmacy, College of Health Sciences, University of Ghana, ${ }^{2}$ Department of Plant and Environmental Biology, College of Basic and Applied Sciences, University of Ghana

Email: eoppongbekoe@ug.edu.gh

Received: 05 Oct 2018, Revised and Accepted: 12 Dec 2020

ABSTRACT

Objective: This study sought to preliminarily investigate the inhibitory effect of metabolites of Aspergillus chevalieri and Trichoderma harzianum on a number of pathogenic bacteria.

Methods: The agar well diffusion method was employed to determine the antimicrobial activity of the fungal metabolites. The test microorganisms were Enterococcus faecalis, methicillin-resistant Staphylococcus aureus (MRSA), Salmonella typhi, Escherichia coli and Pseudomonas aeruginosa.

Results: Both metabolites had broad-spectrum antibacterial activity. All the test organisms were susceptible to the A. chevalieri metabolites except for $S$. typhi. Both $S$. typhi and E. faecalis were however not susceptible to T. harzianum metabolites. P. aeruginosa was highly susceptible to both metabolites with the highest zone of inhibition of $26 \mathrm{~mm}$ for the stock metabolite. This activity was comparable to the standard, $10 \mu \mathrm{g} / \mathrm{ml}$ of ciprofloxacin.

Conclusion: Metabolites of $A$. chevalieri and T. harzianum exhibited broad-spectrum activity, and this can be exploited as a source for novel antibiotics.

Keywords: Antibacterial activity, Antibiosis, Aspergillus chevalieri, Trichoderma harzianum, Culture metabolites

(C) 2021 The Authors. Published by Innovare Academic Sciences Pvt Ltd. This is an open access article under the CC BY license (https://creativecommons.org/licenses/by/4.0/) DOI: https://dx.doi.org/10.22159/ijpps.2021v13i2.39654. Journal homepage: https://innovareacademics.in/journals/index.php/ijpps.

\section{INTRODUCTION}

Infectious diseases caused by bacteria, fungi, and protozoa are common and widespread. They are the primary causes of morbidity, mortality, and a social and economic hindrance for millions of people [1]. According to the World Health Organization (WHO), over 9.5 million people die yearly due to infectious diseases [2]. The rapid emergence of resistant microbial strains has even more so greatly endangered the efficacy of existing antibiotics [3], coupled with the slow rate drug development, the world is unable to keep up with the fight against resistant microbial strains [4]. Worldwide, the emergence of antimicrobial-resistant bacterial strains is increasingly limiting the potency of current drugs, and significantly causing treatment failures $[5,6]$. This has necessitated the fervent need to search for new antibiotics from natural products [7, 8]. Fungi were among the first sources of antibiotics [9] known to man. The discovery and development of the penicillins and cephalosporins from fungal sources, till date, remains some of the most important antibiotics [10] to humankind.

The Fungi Kingdom is the second largest [11] in species, and its members frequently employ the technique of antibiosis in combating bacteria. Antibiosis is the inhibition of one microorganism by the metabolic product of another. The metabolite penetrates the cell and inhibits it by chemical toxicity [12]. Fungi are a rich source of several bioactive compounds, including antibiotics [11]. In that respect, the fungi, Trichoderma harzianum and Aspergillus chevalieri, which are widely available and whose related species are widely known to have the ability to exhibit antibiosis were chosen.

A. chevalieri, belongs to the family Trichocomaceae. It is a storage mould affecting the germination of grains [13]. Invasion of such stored grains is under both hermetic and non-hermetic conditions [14]. A. chevalieri is known for its ability to grow at extremely low water activities [15]. In humans, $A$. chevalieri is an opportunistic pathogen which causes skin infections [16]. Aspergillus species on the other hand, are ubiquitous molds [17], being the most prevalent fungi present in all soils. Many species in this genus are characterized as opportunistic avirulent plant symbionts [18]. Several strains of
Trichoderma such as T. harzianum, T. viride and T. hamatum have been developed as biocontrol agents against fungal diseases of plants [19]. Trichoderma species are also known to exhibit antimicrobial activity against a significant number of bacteria, yeasts, and filamentous fungi [20]. These species release antibiotics and other chemicals that are harmful to pathogens. The aim of this study was to therefore evaluate the inhibitory effect of metabolites of $A$. chevalieri and $T$. harzianum on a number of pathogenic bacteria.

\section{MATERIALS AND METHODS}

\section{Chemicals and reagents}

Potato Dextrose Broth (PDB), Nutrient agar and Nutrient Broth with reference ciprofloxacin, were all obtained from (Oxoid Limited, UK). All other reagents were obtained from standard suppliers.

\section{Culture metabolite preparation}

To obtain the culture metabolites of Aspergillus chevalieri, and Trichoderma harzianum, $3 \mathrm{~cm}$ agar disc of these fungi was inoculated into separate $500 \mathrm{ml}$ Erlenmeyer flask containing $250 \mathrm{ml}$ of sterile Potato Dextrose Broth (PDB). They were prepared in triplicates for each of the test fungi. These were incubated at room temperature for $7 \mathrm{~d}$. The medium was then filtered by suction and pooled together. The collected filtrate was further filtered through a sterile Acrodisc $₫$ Millipore filter $0.2 \mu \mathrm{m}$ (Gelman Sciences, USA). This served as the stock.

\section{Test organisms}

The bacteria and fungi used for the experiments were obtained from the Department of Pharmaceutics and Microbiology of the School of Pharmacy (UGSOP), University of Ghana. The gram-positive bacteria employed in this study were Enterococcus faecalis and methicillinresistant Staphylococcus aureus (MRSA). The gram-negative bacteria employed were Salmonella typhi, Escherichia coli, and Pseudomonas aeruginosa.

\section{Preparation of test solutions}

The undiluted filtrate served as the stock, from which different dilutions were made. This was done by performing serial dilutions of 
$2 \mathrm{ml}$ of the stock solution with $2 \mathrm{ml}$ of sterile Millipore water in sterile 6 well plates. The final test solutions were the stock, 1 in 2 dilution, 1 in 4 dilution, and 1 in 8 dilution.

\section{Antibacterial activity determination}

The antibacterial activity was evaluated using the agar well diffusion method [21]. Twenty millilitres of sterile molten nutrient agar, stabilized at $45^{\circ} \mathrm{C}$ for $15 \mathrm{~min}$ were seeded with $50 \mu \mathrm{l}$ of a 24 hour culture of test bacteria, and aseptically poured into a sterile petri dish and allowed to set. The bacteria and fungi cultures were standardized to a $0.5 \mathrm{McF}$ arland tube. Four wells ( $8 \mathrm{~mm}$ in diameter) equidistant from each other were created with a sterile cork borer (number 5). The wells were then filled with $100 \mu$ l of the stock, 1 in 2, 1 in 4 , and 1 in 8 dilutions of the fungal metabolites. The plates were pre-incubated for $30 \mathrm{~min}$ at room temperature. This was to allow diffusion of the metabolites. The plates were then further incubated at $37{ }^{\circ} \mathrm{C}$ for $24 \mathrm{~h}[22,23]$. Reference antibiotic, ciprofloxacin $(10 \mu \mathrm{g} / \mathrm{ml})$ was used as the control. The procedure was performed in it triplicates and the mean zones of growth inhibition were determined.

\section{RESULTS}

The metabolites from A. chevalieri inhibited the growth of $S$. typhi, and $P$. aeruginosa up to the 1 in 4 dilution. The higher concentration of 1 in 2 dilution of this same metabolite demonstrated activity against MRSA and E. facecalis. No activity was seen against $S$. typhi in the concentrated extract. The 1 in 8 dilution of $T$. harzianum metabolite was active against $E$. coli and $P$. aeruginosa, while activity was seen against MRSA up to the 1 in 4 dilution, however this metabolite was neither active against $S$. typhi nor E. faecalis. The culture metabolites of $A$. chevalieri and T. harzianum had broadspectrum antimicrobial activity against both Gram positive and Gram negative bacteria. That of T. harzianum metabolites was more active at the highest dilution of 1 in 8 than $A$. chevalieri metabolites. Detailed results are displayed in tables 1 and 2. Fig. 1 is the growth of the two fungi under investigation, on potato dextrose agar.

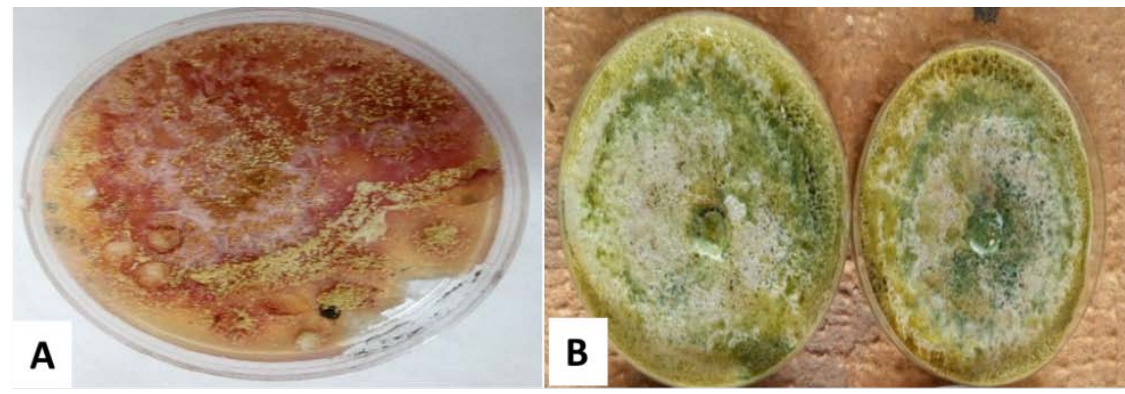

Fig. 1: Aspergillus chevalieri and Trichoderma harzianum on potato dextrose agar

Table 1: Antimicrobial activity of $A$. chevalieri

\begin{tabular}{llll}
\hline Test organism & Dilutions & Zone of inhibition (mm) & Ciprofloxacin (10 $\boldsymbol{\mu g} / \mathbf{m l})$ \\
\hline E. coli & Stock & $19.33 \pm 2.31$ & $38 \pm 1.9$ \\
& 1in 2 & $17.00 \pm 1.00$ & $28 \pm 3.8$ \\
PS. aeruginosa & 1in 4 & $13.00 \pm 0.00$ & \\
& Stock & $25.50 \pm 2.12$ & $42 \pm 2.9$ \\
S. typhi & 1 in 2 & $21.50 \pm 0.71$ & $37 \pm 2.0$ \\
& 1 in 4 & $16.00 \pm 0.00$ & $24 \pm 3.2$ \\
MRSA & Stock & - & \\
& 1 in 2 & $18.67 \pm 1.53$ & $13.33 \pm 1.15$ \\
E. faecalis & Stock & $19.00 \pm 0.00$ & \\
& 1 in 2 & $17.00 \pm 0.00$ & \\
\hline
\end{tabular}

$\mathrm{n}=3$, data given is mean \pm SEM

Table 1: Antimicrobial activity of T. harzianum

\begin{tabular}{llll}
\hline Test organism & Dilutions & Zone of inhibition $(\mathbf{m m})$ & Ciprofloxacin $(\mathbf{1 0} \boldsymbol{\mu g} / \mathbf{m l})$ \\
\hline E. coli & Stock & $27.00 \pm 2.65$ & $38 \pm 1.7$ \\
& 1 in 2 & $22.33 \pm 4.04$ & \\
Ps. aeruginosa & 1 in 4 & $20.00 \pm 0.00$ & \\
& 1 in 8 & $15.00 \pm 0.00$ & $28 \pm 3.0$ \\
& Stock & $27.50 \pm 2.12$ & \\
S. typhi & 1 in 2 & $25.00 \pm 2.83$ & $42 \pm 2.7$ \\
& 1 in 4 & $21.50 \pm 0.71$ & \\
MRSA & 1 in 8 & - & $37 \pm 2.5$ \\
& Stock & - & \\
E. faecalis & 1 in 2 & 24.33 & $24 \pm 3.1$ \\
\hline
\end{tabular}

$\mathrm{n}=3$, data given is mean \pm SEM 


\section{DISCUSSION}

Increasing levels of multidrug resistant microorganisms, coupled with the slow rate of drug development has led to the dire need for new antibiotics [24]. Natural products are known to be rich sources of antimicrobial drugs. They account for over two-thirds of clinically important antibiotics and half of anticancer medicines in use [25]. The inhibition of the pathogenic organism's P. aeruginosa, MRSA, $E$. coli and $E$. facecalis is indicative of the presence of antimicrobially active compounds in these metabolites. The synthesis of antimicrobial compounds by fungal strains is a well-known phenomenon. Fungi strains are known to produce secondary metabolites that aid their virulence and survival against other microorganism [26]. A. chevalieri metabolites inhibited both Gram positive and Gram negative bacteria, hence it can be described as having broad spectrum antibacterial activity. These results agrees with previous reports that Aspergillus species are widely known to produce antibiotics. The antibiotics produced are components of the metabolites and are capable of inhibiting the growth of other microorganisms [11]. Aspergillic acid, penicillic acid and fumagillin [17] are well-known examples of such antibiotics. The metabolites showed significant activity against $P$. aeruginosa which was comparable to ciprofloxacin, the reference antibiotic. $P$. aeruginosa is one of the multidrug-resistant bacteria which is hard to treat. $P$. aeruginosa is known to have resistance to intermediate susceptibility to at least one antibiotic. This high level of resistance is attributable to the multiple intrinsic resistance mechanisms that $P$. aeruginosa may express, which include beta-lactamase production, efflux-mediated and porin-related resistance, and target site modification [24]. These mechanisms are often present in combination, causing a broad range of antibiotics to be rendered ineffective against a given $P$. aeruginosa isolate [27]. In that respect, these fungal metabolites can therefore be exploited to develop new antibiotics. T. harzianum metabolites also inhibited the growth of $E$. coli. $P$. aeruginosa, MRSA but not E. faecalis and $S$. typhi. These results are in accordance with other published data $[18,19,28]$. The suggested mechanisms for biocontrol of Trichoderma species of plant pathogens include antibiosis, lysis, competition, and mycoparasitism [29]. Trichoderma species are also known to exhibit antimicrobial activity against a significant number of bacteria, yeasts, and filamentous fungi [20]. These species release antibiotics and other chemicals that are harmful to pathogens through antibiosis.

\section{CONCLUSION}

In conclusion, Aspergillus chevalieri and Trichoderma harzianum metabolites have good antimicrobial activity against the bacteria $E$. coli, Ps. Aeruginosa and MRSA. This preliminary results indicates that these fungal metabolites contain antimicrobially active compounds that can be exploited for antibiotic production, and development. Further studies to elucidate the antibacterial active compounds can be initiated in that respect.

\section{ACKNOWLEDGEMENT}

The authors will like to thank Mr. Clement Sasu and Mrs. Akosua Okraku of the Department of Pharmaceutics and Microbiology, all of the University of Ghana, for their technical assistance when performing the experiments.

\section{FUNDING}

None

\section{AUTHORS CONTRIBUTIONS}

Both EOB and MW-K contributed equally to this study. JG was responsible for conducting the antimicrobial studies. All authors read and approved the manuscript.

\section{CONFLICT OF INTERESTS}

None

\section{REFERENCES}

1. Gao J, Radwan MM, Leon F, Wang X, Jacob MR, Tekwani BL, et al. Antimicrobial and antiprotozoal activities of secondary metabolites from the fungus Eurotium repens. Med Chem Res 2012;21:3080-6.

2. Peleg AY, Hooper DC. Hospital-acquired infections due to gramnegative bacteria. N Engl J Med 2010;362:1804-13.

3. Golkar Z, Bagasra O, Pace DG. Bacteriophage therapy: a potential solution for the antibiotic resistance crisis. J Infect Dev Ctries 2014;8:129-36.

4. Smith R. The true cost of antimicrobial resistance. Br Med J 2013;346:f1493.

5. Hancock REW. Mechanisms of action of newer antibiotics for gram-positive pathogens. Lancet Infect Dis 2005;5:209-18.

6. Bonjar GHS, Fooladi MH, Mahdavi MJ, Shahghasi A. Broadspectrim, a novel antibacterial from streptomyces sp. Biotechnology 2005;3:126-30.

7. Bosgelmez Tinaz G. Disruption of bacterial cell-to-cell communication (Quorum Sensing): a promising novel way to combat bacteria-mediated diseases. J Marmara Uni Instit Health Sci 2013;3:1.

8. Zgoda JR, Porter JR. A convenient microdilution method for screening natural products against bacteria and fungi. Pharm Biol 2001;39:221-5.

9. Clardy J, Fischbach MA, Currie CR. The natural history of antibiotics. Curr Biol 2009;19:437-41.

10. Karwehl S, Stadler M. Exploitation of fungal biodiversity for discovery of novel antibiotics. Curr Top Microbiol 2016;398:303-38.

11. Majolagbe ON, Aina DA, Omomowo IO, Thomas A. Antimicrobial potentials of soil fungi metabolites, molecular dynamics and their $3 \mathrm{~d}$ protein structural prediction using bioinformatics tool. IJCPR 2020;12:20-6.

12. Wiafe Kwagyan M, Odamtten GT, Obodai M. Possible antibiosis effect of the metabolites of three fungal species resident in rice straw and husk compost on the in vitro radial and vegetative growth by pleurotus ostreatus strain EM-1 and P. eous strain P-31. Int J Curr Microbiol Appl Sci 2015;4:525-38.

13. Abu AA, Ado SA, James DB. Raw starch degrading amylase production by mixed culture of aspergillus niger and saccharomyces cerevisae grown on sorghum pomace. Afr J Biotechnol 2005;4:785-90.

14. Ajayi AA, Adejuwon AO, Obasi CK, Olutiola PO, Peter Albert CF. Amylase activity in culture filtrate of aspergillus chevalieri. IJBCS 2014;8:2174-82.

15. Chen AJ, Hubka V, Frisvad JC, Visagie CM, Houbraken J, Meijer $\mathrm{M}$, et al. Polyphasic taxonomy of Aspergillus (formerly Eurotium), and its occurrence in indoor environments and food. Stud Mycol 2017;88:37-135.

16. Naidu J, Singh SM. Aspergillus chevalieri (Mangin) thom and church: a new opportunistic pathogen of human cutaneous aspergillosis: Aspergillus chevalieri (Mangin) Thorn und Church: Ein neuer opportunistischer erreger von kutaner. Aspergillose Beim Menschen Mycoses 1994;37:271-4.

17. Bramki A, Ghorri S, Jaouani A, Dehimat L, Kacem CN. Antibacterial activity of aspergillus isolated from different algerian ecosystems. Afr J Biotechnol 2017;16:1699-704.

18. Leelavathi MS, Vani L, Reena P. Antimicrobial activity of Trichoderma harzianum against bacteria and fungi. Int J Curr Microbiol Appl Sci 2014;3:96-103.

19. Kucey RMN, Janzen HH, Leggett ME. Microbially mediated increases in plant-available phosphorus. Adv Agron 1989;42:199-228.

20. Hermosa R, Cardoza RE, Rubio MB, Gutierrez S, Monte E. Secondary metabolism and antimicrobial metabolites of trichoderma. Biotechnology and Biology of Trichoderma; 2014. p. 125-37.

21. Agyare C, Bempah SB, Boakye YD, Ayande PG, Adarkwa Yiadom $\mathrm{M}$, Mensah KB. Evaluation of antimicrobial and wound healing potential of Justicia flava and Lannea welwitschii. Evid Based Complement Alternat Med 2013;2013:1-0.

22. Agyare C, Koffuor GA, Boamah VE, Adu F, Mensah KB, AduAmoah L. Antimicrobial and anti-inflammatory activities of Pterygota macrocarpa and Cola gigantea (Sterculiaceae). Evid Based Complementary Altern Med 2012:1-9. https://doi.org/ $10.1155 / 2012 / 902394$. 
23. Gbedema SY, Emelia K, Francis A, Kofi A, Eric W. Wound healing properties and kill kinetics of Clerodendron splendens G. Don, a Ghanaian wound healing plant. Pharmacogn Res 2010;2:63-8.

24. Payne DJ, Gwynn MN, Holmes DJ, Pompliano DL. Drugs for bad bugs: confronting the challenges of antibacterial discovery. Nat Rev Drug Discovery 2007;6:29-40.

25. Newman DJ, Cragg GM. Natural products as sources of new drugs over the $30 \mathrm{y}$ from 1981 to 2010. J Nat Prod 2012;75:311-35.
26. Jakubczyk D, Dussart F. Selected fungal natural products with antimicrobial properties. Molecules 2020;25:911.

27. Nguyen L, Garcia J, Gruenberg K, MacDougall C. Multidrugresistant pseudomonas infections: hard to treat, but hope on the horizon? Curr Infect Dis Rep 2018;20:23.

28. Khayat AS, Al-Aaraji AM. The inhibitory effect of trichoderma crude extract against some human pathogenic bacteria. Plant Arch 2020;20:627-32.

29. Cook R, Baker KF. The nature and practice of biological control of plant pathogens. Am Phytopathol Soc 1983;2:539. 